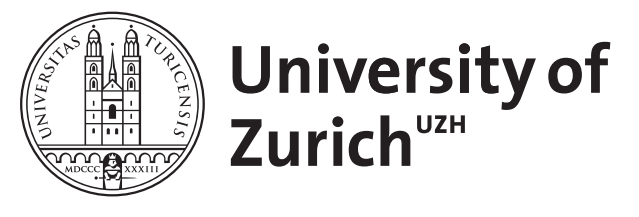

\title{
Reassessing Rigvedic Strata
}

Hellwig, Oliver ; Scarlata, Salvatore ; Widmer, Paul

\begin{abstract}
It is commonly assumed that linguistically the Rigveda is a heterogeneous collection of texts. Since the early days of Vedic scholarship, researchers have tried to correlate grammatical properties with individual parts of the Rigveda, aiming at identifying layers and strata. In this article we review stratifications proposed in previous literature and assess the support for these strata by performing statistical analyses with allomorphic linguistic features that have been claimed to bear signals of stratification. In addition, we run a cluster analysis exploring how the books are grouped given the same allomorphic linguistic data. Our results show that once we control for metrical positioning, prosodic structure, and content, the allomorph distributions do not lend significant support for any of the proposed stratifications. Moreover, the cluster analysis favors the assumption that book 10 occupies a special position, but overall differences across the ten books of the Rigveda are not substantial.
\end{abstract}

DOI: https://doi.org/10.5913/jaos.141.4.2021.ar032

Posted at the Zurich Open Repository and Archive, University of Zurich

ZORA URL: https://doi.org/10.5167/uzh-211218

Journal Article

Published Version

Originally published at:

Hellwig, Oliver; Scarlata, Salvatore; Widmer, Paul (2021). Reassessing Rigvedic Strata. Journal of the American Oriental Society, 141(4):847-865.

DOI: https://doi.org/10.5913/jaos.141.4.2021.ar032 


\title{
Reassessing Rigvedic Strata
}

\author{
Oliver Hellwig, Salvatore Scarlata, and Paul Widmer \\ UNIVERSITY OF ZURICH
}

\begin{abstract}
It is commonly assumed that linguistically the Rigveda is a heterogeneous collection of texts. Since the early days of Vedic scholarship, researchers have tried to correlate grammatical properties with individual parts of the Rigveda, aiming at identifying layers and strata. In this article we review stratifications proposed in previous literature and assess the support for these strata by performing statistical analyses with allomorphic linguistic features that have been claimed to bear signals of stratification. In addition, we run a cluster analysis exploring how the books are grouped given the same allomorphic linguistic data. Our results show that once we control for metrical positioning, prosodic structure, and content, the allomorph distributions do not lend significant support for any of the proposed stratifications. Moreover, the cluster analysis favors the assumption that book 10 occupies a special position, but overall differences across the ten books of the Rigveda are not substantial.
\end{abstract}

\section{INTRODUCTION}

Ever since the early work of Bergaigne $(1886,1887)$ and Oldenberg $(1888)$ on the organization and history of the Rigveda it has been commonly assumed that this oldest testimony of Indian literature is a collection of texts that consists of heterogeneous parts. While largely belonging to the same religious and cultural sphere, its individual parts may differ in terms of content, purpose, geographical origin, authorship, age, meter, and organizational principles, just to mention a few aspects (see, among others, Arnold 1905; Gonda 1975; Witzel 1995, 1997, 2003; Jamison and Brereton 2014; Brereton and Jamison 2020). Right from the start of Vedic studies, these aspects were also correlated with linguistic variation found in different parts of the Rigveda. With respect to age, for example, particular linguistic phenomena are claimed to be more recent developments within Indo-Aryan or Indo-Iranian because they occur in conspicuous frequency in book 10 of the Rigveda, which is often assumed to be of later origin than the rest of the text (see Wackernagel and Debrunner 1930-57: I.4-5 with exx. and lit.). Based on contextual information provided by the textual unit they occur in, other linguistic particularities are said to be of diatopic origin (see, e.g., Witzel 1989).

Most of these claims deal with very particular linguistic phenomena and are based on careful qualitative argumentation considering evidence that relates both to content and comparative historical linguistics. However, there exists variation in the linguistic data that is possibly more or less randomly distributed across the individual parts of the Rigveda. To the best of our knowledge, it has never been tested whether the qualitative linguistic arguments actually stand up to scrutiny when tested against chance. Capitalizing on the newly available functionalities provided by the VedaWeb (Kiss et al. 2019), we take a closer look at seven types of morphological variation in Vedic studied since the early days of Vedic scholarship and probe into possible correlations between these variants and textual layers in the Rigveda that have been proposed in previous literature. This procedure enables us to independently clarify the status of both presumed textual layers and linguistic variation within the Rigveda.

This paper therefore has two aims. From a linguistic and textual perspective, it reassesses the discriminative power of a set of allomorphs that were widely used in previous 
research for inducing a stratification of the Rigveda. From a methodological perspective, it describes how such a study can be performed using digital resources such as VedaWeb and standard quantitative methods. Data and scripts with which these tests are performed, as well as supplementary material are available for replication on gitlab (https://gitlab.uzh.ch/paul. widmer/rigveda-layers).

The rest of this paper is structured as follows. In section 2 we give a concise recap of the methods and principal findings of previous scholarship. Section 3 provides a description of our data and methods. The results are presented in section 4 , followed by a discussion in section 5 .

\section{RELATED WORK}

The degree of linguistic heterogeneity in the Rigveda has given rise to a vast number of publications. In this section, we will concentrate on approaches that try to derive a stratification of the Rigveda by applying numerical methods to linguistic data.

Research into the internal stratification of the Rigveda is closely connected with its relationship to the Atharvaveda. Roth (1856: 18) noted early on that the content of Rigveda 10 resembles that of the Atharvaveda, and the likely assumption of Rigvedic citations in the Atharvaveda led Bloomfield to the conclusion that the Atharvaveda must be later than the Rigveda (Bloomfield 1899: 45-47). The fundamental ideas underlying many numeric approaches to the stratification of the Rigveda were formulated by Lanman. Starting from an initial intuition about early and late traits of the text which include "contents, vocabulary, phraseology, meter, place in the collection, etc." (Lanman 1872: 581), Lanman proposed to single out early parts of the Rigveda on the basis of these traits. In a subsequent step he examined these parts by checking them numerically against the distribution of several morphological features he assumed to be chronologically stratified. He illustrated this approach (1872: 577-80) by comparing the ratios of the allomorphs $-\bar{a} /-a u,-\bar{a} s a s /-\bar{a} s,-\bar{a} /-\bar{a} n i$, -ebhis/ -ais for the Rigveda and the Atharvaveda. Since he observed an uneven distribution of the allomorphs (i.e., $-a u,-\bar{a} s$, etc.) across the two texts, he proposed to apply the same method for inducing a relative chronology of the ten books of the Rigveda. Lanman's numerical method, which was used in many later publications, is based on a number of implicit assumptions. From a quantitative perspective three of them need to be addressed more explicitly.

First, Lanman used ratios of allomorph frequencies for investigating Rigvedic strata, but did not test if they point to statistically significant differences (see section 3.3 of this paper). This does not diminish the value of Lanman's groundbreaking work by any means. Adequate statistical methods were not available at the time, and only few later studies have applied statistical methods to questions of chronology or authorship attribution in Vedic or Sanskrit literature (for an overview see Fosse 1997: 16-57).

Second, Lanman created a merged ranking of the ordered series of individual features by highlighting identical or similar rankings of books. Again, this method was the best Lanman could do when he wrote his paper. However, inducing a joint ranking from multiple variables requires a multivariate method.

Third, when ordering the data, Lanman assumed that the frequencies of the examined allomorphs decrease monotonically over time. While many linguistic developments are indeed supposed to occur with monotonically increasing or decreasing frequencies (Blythe and Croft 2012), it is well known that there also exist many diachronic (and/or registerrelated) distributions that deviate from such a trajectory; see, for instance, Best 2003: 19 on the diachronic distribution of the Latin pronoun hic; Fleischer 2012: 188-89 on gender 
agreement phenomena in the history of High German; and, more generally, Nevalainen 2015. Although assuming monotonic trends may be justified in many cases, it constitutes a strong axiom that does not need to be true a priori but must be tested in each case. Moreover, in a corpus such as the Rigveda, the overall monotonic increase or decrease of an allomorph in the history of Vedic Sanskrit can easily be masked, or even inverted, because of the small and heavily skewed sample.

As for specific stratifications of the Rigveda, Oldenberg based his proposal mainly on the arrangement of the hymns, and used linguistic information only as an ancillary criterion, explicitly including Lanman's line of argumentation (Oldenberg 1888: 268, 333). According to him, the hymns RV 1.51-RV 7 constitute the core of the text (Oldenberg 1888: 249-60), to which, as the first extension, RV 1.1-50 and possibly RV book 8 were added (Oldenberg 1888: 262). The second extension identified by Oldenberg, i.e., RV book 9, contains the Soma hymns, which were extracted from RV 1-8 (Oldenberg 1888: 263), while the third major extension consists of RV book 10 (Oldenberg 1888: 264-70). The fourth and last extension comprises the appendices to the Family Books 2-7, which are presumed to be younger than the material in RV 10 (Oldenberg 1888: 265). It is important to mention that, according to Oldenberg, only the last two extensions (RV 10, appendices to RV 2-7) are linguistically different from the rest of the text (Oldenberg 1888: 270), which results in a threefold stratification (1-9 without appendices) - (10) - (appendices to RV 2-7). A similar method for recovering appended material was used by Grassmann (1876-77: II 1: 185, 288), who considered the metrical structure and the content of Rigvedic hymns.

Arnold (1905: 251) adopted Lanman's method, but considered a much wider array of features. Arnold claimed to induce a chronological stratification of the Rigvedic books by independently studying linguistic and metrical features (Arnold 1905: ix) and to form strata in the text by identifying coherent parts in which "certain features of language or metre recur with much greater frequency than in other parts" (Arnold 1905: 4; data on pp. 269-88). In the same way as Lanman, Arnold did not assess the statistical significance of the differences in observed counts. Again, one has to consider that the necessary statistical methods were either not yet developed or not known outside the emerging community of biometricists and biostatisticians at his time.

Conceptually, Wüst (1928) chose an approach similar to those of Lanman and Arnold, but relied on stylistic criteria. Starting from preconceived ideas concerning cultural evolution, he considered expressivity in form and content ("Schwellstil," e.g., secondary vrddhiderivatives, number games ["Zahlenspiele"], adjectives with philosophical meanings, or hapax legomena) as indicators of more evolved and therefore younger linguistic material (Wüst 1928: 14). Based on the relative frequencies of these indicators, Wüst (p. 165) presented a relative chronology of the ten Rigvedic books, in which RV 3, 4, 7, and 9 are labeled as "old" and the remaining books as "young."

The approach of Poucha (1942a, 1942b, 1944), who tried to derive a chronology of the Rigvedic books by counting lexical units, was generally discarded (see, e.g., Gonda 1975: 28) due to the subjective criteria by which he selected the relevant features (see the discussion of old and young words, Poucha 1942b: 128-38) as well as to the unclear mode of presenting his results.

More recently, Witzel (1997) proposed a cumulative stratification of the Rigveda that combines ideas brought forward by Oldenberg (1888: 249-70) with historical references found in the text, resulting in the distinction of five main layers (see below).

Ultimately, all proposals made so far draw - at least tacitly - on the ideas developed by the early pioneers Lanman, Oldenberg, and Arnold. Right from the beginning, their mul- 
tivariate approach included allomorphic variation as a key parameter, but its contribution to the stratifications proposed has never been evaluated. In fact, most Vedicists subscribe to the view that the Rigveda is somehow stratified, but the empirical basis of this claim is usually not discussed. This is evidenced by the fact that recent scholarship mostly presents stratifications as common knowledge but refrains from discussing their linguistic particulars or leaves it open; examples include Cardona (2017: 310: "It is generally accepted that books 2-8, each ascribed to a particular family, make up the most ancient core of the Rgveda") as well as Porzig (1923: 210), Thieme (1964: 4), Hoffmann (1967: 36-37), Gonda (1975: 8-14 ), Witzel and Goto (2007: 443), Dahl (2010: 2), Keydana (2013: 1), Lowe (2015: 2), Brereton and Jamison (2020: 18-19, 25-26, 29), to mention but a few. Critical voices have been raised as well, doubting that there is any exploitable phonological and morphological evidence (Pisani 1929).

For both views an empirical validation is missing. For the allomorph variation studied in this paper, such a validation is even more important, as some variants were arguably inherited and therefore at the disposal of the Rigvedic poets at any time. The distribution of variants may thus be founded in differences of style, origin of poets, individual preferences, etc., rather than in chronology alone.

\section{DATA AND METHODS}

In this section we first specify the proposed textual stratifications to be assessed and the linguistic data we consider, and then elaborate on the statistical tests we perform.

\subsection{Textual Layers}

From among the various proposals about strata in the Rigveda that were brought forward in previous literature, the following are taken into consideration in this paper:

1. Books: The RV consists of ten mandalas, lit. '(song) circles, cycles', corresponding to our designation 'books'; see Jamison and Brereton 2014: I.10. We test if the counts of allomorphs differ with respect to these ten books.

2. Strata identified by Arnold 1905, foreshadowed in Arnold 1897b: 237 and passim, and idem 1897a: 335-43 and passim: Arnold split the Rigveda into five chronologically successive periods, labeled archaic (A), strophic $(\mathrm{S})$, normal $(\mathrm{N})$, cretic $(\mathrm{C})$, and popular $\left({ }^{*}\right)$. These periods are labeled with uppercase letters (e.g., S) if they are induced by considering metrical as well as linguistic criteria and by lowercase letters (e.g., s) if only metrical criteria apply. This method produces a total of ten different strata (A, a, S, s, . .).

3. Annexes identified by Oldenberg ("Anhänge"): We test the threefold stratification (1-9 without the appendices) - (10) - (appendices); see discussion above.

4. Annexes identified by Grassmann ("Anhänge"): The appended hymns are found in Grassmann 1876-77: I.523-68, II.41-503.

5. Strata proposed by Witzel on the basis of Oldenberg's work: Witzel (1997: 262-64) proposed five main layers: (1) The family books 2-7; (2) 1.51-191 (non-strophic, Ānigirasa), 8.1-66 (strophic, Kāṇva); (3) 1.1-50 (strophic, Kāṇva), 8.67-103 (strophic, Āñgirasa); (4) the Soma hymns in RV 9; (5) RV 10.

6. Rigveda (1-9) vs. (10): This split was among the first ones proposed; see, e.g., Roth (1856: 18), acknowledged by Wackernagel (1896: xiv n. $1=$ Wackernagel and Debrunner 1930-57: I.4 n. 45). 


\subsection{Linguistic Features}

As was mentioned above, likely drivers of stratifications are spatio-temporal as well as sociocultural differences at the time when the purported strata were composed. In order to test for distinct strata based on linguistic features we need to ensure that any observed uneven distribution in the Rigveda is conditioned by the restricted availability and biased choice between isofunctional variants (allomorphs) given possible spatio-temporal and sociocultural differences. We collect such allomorphs from previous research and focus on the following seven pairs which occur at a sufficient frequency.

1. $a$-stem NOM./VOC.PL.M endings - $\bar{a} s a s$ vs. $-\bar{a} s$ (Macdonell 1910: 260; Wackernagel and Debrunner 1930-57: III.100-102). The status of -āsas/-ās as isofunctional allomorphs has recently been challenged by Hill (2018) and Coenen and Frotscher (2020). Since the authors start from assumptions that are not generally shared, we still chose to include this pair. Running our analysis without $-\bar{a} s a s /-\bar{a} s$ (not reported) did not substantially change the results.

2. $a$-stem NOM/ACC.PL.N endings $-\bar{a}$ vs. $-\bar{a} n i$ (Macdonell 1910: 260-61; Wackernagel and Debrunner 1930-57: III.103-5). The VedaWeb online interface does not, for the time being, support queries that distinguish these variants by their contextual case specification (NOM/ ACC). Since Lanman made no attempt to differentiate between the two cases, we decided not to disambiguate them manually. While this decision is a possible source of confusion, it has the advantage that the raw counts per allomorph are higher, which leads to potentially more stable statistical results. Unlike Arnold (1897a: 298) we include occurrences of consecutive forms bearing the variant endings.

3. $u$-stem NOM/ACC.PL.N endings $-\bar{u}$ vs. $-\bar{u} n i$ (Macdonell 1910: 298; Wackernagel and Debrunner 1930-57: III.160-62; with regard to case, see above).

4. $a$-stem INS.PL -ebhis vs. -ais (Macdonell 1910, 261; Wackernagel and Debrunner 193057: III.105-8).

5. $a$-stem INS.SG - $\bar{a}$ vs. -ena (Macdonell 1910: 256-57; Wackernagel and Debrunner 1930-57: III.90-92).

6. SBJV.SG primary vs. secondary endings (Macdonell 1910: 316; García Ramón 2009).

7. Interrogative pronoun kát vs. kím (Macdonell 1910: 303; Wackernagel and Debrunner 1930-57: III.559; Oldenberg 1888: 270; also see Etter 1985). Historically, this pair is especially interesting since Oldenberg used it explicitly as one criterion to support Roth's split between the books $1-9$ and book 10 (see section 3.1 above).

In the Rigveda $a$-stem pronouns exclusively show the pronominal instrumental endings -ena (Wackernagel and Debrunner 1930-57: III.498) and -ebhis (Wackernagel and Debrunner 1930-57: III.502) and thus do not exhibit allomorph variation, as required in this paper. We therefore exclude the instrumental forms of pronouns from the data set.

Other allomorphic variants adduced in former studies were dismissed in this study for various reasons. The alternations between isofunctional $-a u$ and $-\bar{a}$ in the dual (Arnold 1897a: 298 ) and in the locative singular are not taken into consideration because these variations interact with sandhi rules to an extent we are not able to control (Malzahn 2001; Dawson 2005). Additionally, there is reason to assume that at least a part of this variation is not due to strata-related distributions, but was only introduced by Śākalya during the transmission process (Pirart 2001).

The status of the purported $\bar{a}$-stem INS.SG $-\bar{a}$ vs. $-a y \bar{a}$ variation (Macdonell 1910: 264; Wackernagel and Debrunner 1930-57: III.115-19) is unclear, and the fact that most of the words ending in $-\bar{a}$ occur in this form only raises concern. Moreover, some forms in $-y \bar{a}$ with the meaning 'wishing for' are classified as INS.SG-forms of $\bar{a}$-stems by Grassmann (1873-75), but alternative analyses are readily available. In particular they could equally be 
formed with the adverbial suffix $-y \bar{a}$ (Wackernagel and Debrunner 1930-57: III.75-78), and other morphonological processes such as haplology may have interfered (i.e., INS.SG $-y a y \bar{a}$ $-y \bar{a}$, -tāta $-t \bar{a}$; see Wackernagel and Debrunner 1930-57: III.116-17). Note also the possible formal identity of the INS.SG of $a$-stems and $\bar{a}$-stems. A separate pilot study (not included here) has shown that the distributional properties of this allomorph are heavily dominated by a few lexemes (esp. dhấrā- 'stream' in RV 9) so that the differentiating strength of this allomorphic variation is limited.

Other potential allomorphic alternations presented by Arnold (1897a: 307-10) are omitted since there are too many confounding factors. The most promising one, i.e., variation in $i$ - and $u$-stems, for example, is certainly as much driven by purely grammatical properties (inflectional and lexical classes) as by sociocultural circumstances (e.g., authorship, content, target audience, age, metrics, geographical origin, etc.).

We extract the data using the VedaWeb query and export functions (https://vedaweb.unikoeln.de/rigveda/search). For further processing and analyzing these data, we use the R environment (R Core Team 2018), which provides packages for most of the statistical methods applied in this paper.

\subsection{Quantitative Methods}

There is a long tradition of using frequencies of linguistic phenomena for inducing text layers in Vedic studies. One important question, however, remained unanswered in most of these studies: Are the differences in such frequencies due to systematic linguistic differences between the examined text samples, or are they only caused by random effects and thus finally by chance? In order to better understand the distributions of linguistic variants across the Rigveda and, at the same time, to control the influence of random effects present in this small sample, we use standard statistical tests of significance and assess how compatible the observed data are with the specified statistical models.

While the tests we apply differ strongly in their internal setup and design, they follow the same basic strategy, which is encoded in the three statistical key terms alternative hypothesis, $p$-value, and significance. The first step of statistical testing consists in formulating a difference hypothesis ("alternative hypothesis"), which claims that two or more populations differ with regard to one or multiple features. Such a hypothesis usually formulates a research idea (e.g., RV 10 differs from the remaining books with regard to its distribution of allomorphs). In the second step, a statistical test is applied to the observed data. This test yields an error probability, the so-called p-value. This p-value quantifies the probability with which the alternative hypothesis is erroneously accepted as true, and it follows that a low p-value supports the alternative hypothesis and therefore the research idea. If the calculated p-value is below a conventional threshold, it is called significant.

As a worked-out example, consider the p-value of 0.038 that Table 3 below reports for the allomorph kát/kim and the stratification (1-9) (10), i.e., RV 1-9 vs. RV 10. This p-value encodes the following experimental setup:

- The alternative hypothesis claims that the two strata RV 1-9 and RV 10 have different ratios of kát vs. kim and that these differences are so pronounced that they cannot be caused solely by chance. Note that we do not make any assumptions about what a "pronounced difference" may quantitatively amount to; we will come back to this aspect in a moment when discussing Cramér's index.

- In order to test the probability of the alternative hypothesis, a $2 \times 2$ table of counts is compiled - the rows of which contain the counts of the allomorphs in the two hypothesized 
strata (columns). The top-left cell of this table thus contains the frequency of kát occurring in RV 1-9, the top-right cell that of kát in RV 10, etc.

- Now, a Freeman-Halton test (Agresti 1992) is applied to this table of counts. The p-value of 0.038 produced by this test indicates that there is a chance of $0.038=3.8 \%$ to err when accepting the alternative hypothesis as true, i.e., when claiming that kát and kim occur with different frequencies in the two strata.

- Let the significance threshold be set to $0.1=10 \%$; this means that the researcher wants to accept (and perhaps publish) a wrong hypothesis with a probability of maximally $10 \%$.

- In this setting, the alternative hypothesis (RV 1-9 and RV 10 differ with regard to kát/ kim) can be accepted because the p-value of 0.038 (or 3.8\%) is lower than the significance threshold of 0.1 . Usual error levels used in statistical literature are $0.1(10 \%)$ or even 0.01 $(1 \%)$. Values in Table 3 that are above 0.1 therefore indicate that there are no significant differences for a given stratification (column) and a given allomorph (row).

- While the p-value of 0.038 may sound like a convincing result, Table 3 also reports Cramér's index which is 0.19 for kát/kím and (1-9) (10). This index quantifies the correlation between two categorical variables (strata and allomorphs) and ranges from 0 (low) to 1 (high correlation; see, e.g., Bortz and Lienert 2003: 247-50). The reported value of 0.19 is close to its lower bound, which indicates that the correlation of kát and kim with these two strata may be weaker than suggested by the p-value of the Freeman-Halton test. Such a basically contradicting outcome (the significance test points to a strong difference while Cramér's index does not) can occur in various situations. One possible explanation has already been hinted at above: As we did not (and, actually, cannot) quantify what a "pronounced difference" means for the given problem, the Freeman-Halton test may have detected a systematic, yet tiny numeric difference. Such a situation can occur when the tested counts are comparatively large; just consider the following fictive example where two features in the rows are evaluated for two strata:

\begin{tabular}{|l|l|l|}
\hline & Stratum 1 & Stratum 2 \\
\hline Feature 1 & 1 & 2 \\
\hline Feature 2 & 3 & 2 \\
\hline
\end{tabular}

\begin{tabular}{|l|l|l|}
\hline & Stratum 1 & Stratum 2 \\
\hline Feature 1 & 10 & 20 \\
\hline Feature 2 & 30 & 20 \\
\hline
\end{tabular}

- The right table has the same ratios as the left one $\left(\frac{1}{2}=\frac{10}{20}\right.$ etc.), but its values have been multiplied by the factor of 10 . Now, the Freeman-Halton test produces a p-value of 1 for the left table, indicating no significant differences between the strata at all, but a significant p-value of 0.0385 for the right one, whereas Cramér's index is 0.2582 and thus quite low for both. This index can therefore help to detect cases in which a test becomes significant just due to a large sample.

- Another possible explanation for the seemingly contradicting results of Freeman-Halton and Cramér's index may be that the distributions of the allomorphs are influenced by other factors than the strata. Such a hypothesis gets support from a Cochran-Mantel-Haenszel test (CMH test; see Agresti 2007: 114-15), which considers metrical position as one possible control variable able to influence the distributions of kát/kim. When the influence of the metrical position is, so to say, subtracted from the distributions of kát and kim, the p-value rises from 0.038 to 0.059 , as reported in the second compartment of Table 3 . When one considers the metrical position as an influencing factor, there is now a chance of $5.9 \%$ to err when claiming that the counts of kát/kím differ in (1-9) (10) - not a dramatic increase of the error probability, but nevertheless much closer to the significance level of $10 \%$ than the result of the Freeman-Halton test and thus a reason for caution. 
To our knowledge, previous scholarly stratifications of the RV have been done "by hand," meaning that scholars collect frequencies or ratios of certain features in a table and then try to group this table by similar values, guided by their understanding of the underlying linguistic and literary processes. Such an approach can lead to biased results (observer bias) and is moreover only feasible for small amounts of linguistic data. Apart from assessing previous stratifications, we therefore also examine if any stratification of the Rigveda emerges from the allomorph distributions considered in this paper. We resort to cluster analysis in section 4.3 (see Tan et al. 2019 for a general introduction) and use a binary clustering model for inducing groups of Rigvedic books with similar distributions of allomorphs without manual intervention. ${ }^{1}$ Since the number of items that need to be clustered is small-we aim at grouping the ten books of the RV-we can test all 115,975 possible partitions of the ten Rigvedic books and thus provide an exact solution of the clustering problem. The induced groups are ranked using the Bayesian Information Criterion (BIC; Schwarz 1978), which weights the goodness of a grouping (how well can books of the RV be distinguished based on allomorph frequencies?) against its complexity (how many groups are generated? fewer are better). Note that the statistical tests and cluster analysis represent opposite approaches: While statistical tests are used to assess existing scholarly theories about the composition of the Rigveda, cluster analysis aims at constructing textual layers solely on the basis of the observed linguistic data.

\section{ANALYSIS AND RESULTS}

\subsection{Exploratory Analysis}

Table 1 provides basic statistical properties of the examined features.

Table 1. Basic statistical properties of the examined features

\begin{tabular}{|c|c|c|c|c|c|c|}
\hline \multirow[b]{2}{*}{ Feature } & \multirow[b]{2}{*}{ Total } & & \multicolumn{2}{|c|}{ Type-token ratio } & \multicolumn{2}{|l|}{ Position } \\
\hline & & & $\mathrm{p}$ & CI & $\mathrm{p}$ & $\mathrm{CI}$ \\
\hline$-\bar{a} /-\bar{a} n i$ & 1684 & 1080 & $.027^{*}$ & .039 & $<.001 * * *$ & .138 \\
\hline$-\bar{u} /-\bar{u} n i$ & 80 & 127 & .298 & .073 & $.006^{* *}$ & .230 \\
\hline -ebhis/-ais & 498 & 681 & .067. & .046 & $<.001 * * *$ & .381 \\
\hline$-\bar{a} /$-ena & 81 & 785 & 1.000 & .000 & $001 * * *$ & .273 \\
\hline$-\bar{a} s a s /-\bar{a} s$ & 1034 & 2241 & .225 & .019 & $<.001 * * *$ & .242 \\
\hline kát/kím & 47 & 78 & & & & \\
\hline prim./sec. & 262 & 928 & $<.001 * * *$ & .086 & $.025^{*}$ & .079 \\
\hline - ACT.SG & 247 & 717 & $.009 * *$ & .077 & $.005^{* *}$ & .103 \\
\hline - MED.PL & 14 & 41 & .102 & .213 & .361 & .221 \\
\hline
\end{tabular}

The column "Total" gives the total counts for each allomorph according to our data. The two entries in the column "Type-token ratio" report the p-value of a Freeman-Halton randomization test for the lexical richness (without leading zeros) as well as Cramér's index (CI), i.e., the association strength between the variables (see the example in section 3.3 and the discussion there). The column "Position" gives the p-value of a Freeman-Halton test that

1. The mathematical details of this model are given in the supplementary material. 
assesses if two allomorphs occur with equal frequencies in verse-initial, intermediate, and verse-final positions, as well as the respective value of Cramér's index. Columns 3 and 4 remain empty for kát/kim as the type-token ratio for lexemes is not defined (col. 3) and both words have the same prosodic structure (col. 4). Asterisks and dots indicate the significance levels: . $=10 \%, *=5 \%, * *=1 \%, * * *=0.1 \%$.

Before starting the evaluation, we need to discuss if the distributions of the allomorphs are influenced by factors different from the possible stratifications reviewed in section 3.1. We use the Freeman-Halton test (see section 3.3) for examining two obvious factors: lexical preferences and metrical constraints. Lexical preferences are quantified by collecting typetoken ratios for each allomorph, i.e., the number of lexical types (lemmata) each allomorph is applied to, and the respective number of tokens. Consider, for example, that the allomorph $-\bar{a}$ sas would only be applied to the two words devá- $(5 \times)$ and ás $v a-(3 \times)$. In this case, we would obtain a type-token ratio of $\frac{2}{5+3}=0.25$. A type-token ratio that comes close to 1 indicates that an allomorph is applied to a varied vocabulary, while one approaching 0 suggests a limited lexical distribution. Comparing the type-token ratios of two allomorphs thus gives a first clue as to whether one of them may be lexically more restricted than the other. Metrical constraints, the second set of factors, are quantified via a tripartite positional distinction within a verse line: verse-initial, verse-final, and verse-medial (i.e., neither initial nor final). ${ }^{2}$ For both factors we assemble count tables with allomorphs in the rows and the factor levels (types and tokens for the lexical richness, the three positions in a verse line for the metrical constraints) in the columns, similar to those shown in the fictive example in section 3.3. Table 1 reports the p-values of the Freeman-Halton tests and the values of Cramér's index for these count tables. In the following we discuss those results in Table 1 that have p-values of less than $1 \%$; this means with at least two asterisks. Our discussion follows the line of argumentation sketched in section 3.3.

The lowest p-values, i.e., the most significant indications of differing distributions, are obtained for the positional distributions of the inflectional endings. These values suggest that the respective allomorphs are unevenly distributed across positions in a verse, which makes sense given their different prosodic structures. However, one needs to consider that the values of the respective Cramér's indices are comparatively low, leaving aside the one for-ebhis/-ais, to which we will return in section 4.2. This means that the low p-values do not necessarily reflect systematic positional differences, but may also be due to the large sample sizes, which can produce misleading p-values, as discussed in section 3.3. We therefore inspect in detail the metrical distributions of the allomorph pair $-\bar{a} /-\bar{a} n i$ for the words bhúvana- 'being, world' and rocaná- 'light, realm of light' as a test case for possible interacting factors (data in Table 2).

Due to their metrical makeup $(\smile \smile-(\smile)$ ), neither bhúvanā nor bhúvanāni meets the metrical requirements for verse-final position in dimeter (eight syllables) or trimeter (eleven or twelve syllables) verses, bhúvanā in RV 10.25.6 being an outlier. In intermediate position, i.e., when the verse neither starts nor ends with bhúvanā(ni), both forms of bhúvana- are only used in trimeter verses, and they show a strong preference to start after the caesura at the fifth syllable (bhúvanāni: 53/57, bhúvanā: 24/34). rocană with its long first metrical unit, however, can occupy an intermediate position in both dimeter and trimeter verses. Moreover, rocanăni fits into the cadence of meters with eleven syllables (the only position it is attested in), and rocaná fits into that with eight or twelve syllables.

2. The position of word forms which is retrieved through VedaWeb is of course a mere approximation of their place within the metrical units familiar to Vedicists, i.e., opening, break, and cadence. 
Overall, the different distributions over the metrical positions appear to be caused, to a substantial degree, by the different prosodic structures of the two words. However, this result explains only a part of the observed variation, as it neither accounts for the complete absence of rocanáni in intermediate position, nor for the preference for bhúvanāni in the same position. These details may indicate that there exist intricate interactions between the meter, the vocabulary, and the choice of allomorphs that cannot be examined in detail in this paper. We therefore zoom in on the prosodic structure as well as the metrical position in the evaluation in section 4.2, in which the influence that prosody and meter exert on the correlation between allomorphs and strata will be quantified with a Cochran-Mantel-Haenszel test (CMH test; see section 3.3). This test assesses whether the ratios of allomorphs still differ significantly when the influence that the metrical position and the prosody (control variables) exert on their distributions is taken into account. Since the comparison of bhúvana- and rocaná- suggests that prosody and meter counterbalance some observed effects, we expect that the $\mathrm{CMH}$ tests will yield less significant results (i.e., higher p-values) than the tests performed without the control variables, as shown in Table 2.

Table 2. Allomorph distributions of two words, grouped by their metrical positions

\begin{tabular}{lccccccc}
\hline & \multicolumn{2}{c}{ Initial } & \multicolumn{3}{c}{ Intermediate } & \multicolumn{2}{c}{ Final } \\
\cline { 2 - 8 } Word & $-\bar{a}$ & $-\bar{a} n i$ & $-\bar{a}$ & $-\bar{a} n i$ & $-\bar{a}$ & $-\bar{a} n i$ \\
\hline bhúvana- & 2 & 2 & 34 & 57 & 1 & \\
rocaná- & & & 16 & & 10 & 3 \\
\hline
\end{tabular}

With regard to the type-token ratios (columns $3 \mathrm{a}$ and $3 \mathrm{~b}$ of Table 1), it can be observed that the p-values of the Freeman-Halton tests (column 3a) are in general higher than those for the metrical position (column 4a), indicating that the allomorphs do not differ too much in their lexical diversity. Notably, even in those cases in which the p-values are (highly) significant, as, for instance, for prim./sec., the corresponding values of Cramér's index (column $3 b)$ are close to zero and thus do not point to systematic differences in the lexical richness. Both observations suggest that the interaction between the allomorph distributions and the lexicon (type-token ratio) should not distort the overall image to a major degree. Contrary to prosody and meter, the lexicon will therefore not be assessed as an additional control variable in section 4.2.

\subsection{Proposed Stratifications}

In this section we test if the ratio of a pair of allomorphs inside a proposed stratum differs from its ratio outside this stratum to a significant degree, and if individual pairs of allomorphs thus support proposed strata. As exemplified in section 3.3, we compile tables that record the counts of the allomorphs inside and outside each stratum (e.g., $-\bar{a} /-\bar{a} n i$ inside and outside of Oldenberg's appendices) and apply Freeman-Halton tests to the resulting tables. The p-values of these tests, which are reported in the upper compartment of Table 3, now give the probabilities with which one would wrongly claim that the compared strata are different. As for the exploratory analysis in section 4.1, we also report the respective values of Cramér's index (in square brackets) that can reveal spurious correlations. 
Table 3. Results for distribution of allomorphs over various scholarly partitions of the Rigveda

\begin{tabular}{|c|c|c|c|c|c|c|}
\hline Features & Book & Arn & Old & Gra & Witzel & $(1-9)(10)$ \\
\hline \multicolumn{7}{|c|}{ No adjustments } \\
\hline$-\bar{a} /-\bar{a} n i$ & .397 & $.001^{* * *}[.11]$ & .655 & .450 & .734 & .633 \\
\hline$-\bar{u} /-\bar{u} n i$ & $.075 .[.28]$ & $.003^{* *}[.32]$ & .744 & $.045^{*}[.14]$ & $.088 .[.20]$ & .340 \\
\hline -ebhis/-ais & .277 & .107 & .305 & .197 & $.035 *[.09]$ & .101 \\
\hline$-\bar{a} /$-ena & .629 & $.001^{* * *}[.19]$ & .149 & .446 & .760 & .323 \\
\hline$-\bar{a} s a s /-\bar{a} s$ & $.001^{* * *}[.09]$ & $.001^{* * *}[.14]$ & $.004^{* *}[.06]$ & .116 & $.001^{* * *}[.08]$ & $.001^{* * *}[.06]$ \\
\hline kát/kim & $.028^{*}[.37]$ & $.001^{* * *}[.48]$ & $.010^{*}[.26]$ & $.064 .[.17]$ & $.030^{*}[.29]$ & $.038^{*}[.19]$ \\
\hline prim./sec. & .226 & $.001^{* * *}[.15]$ & .569 & .421 & $.023^{*}[.10]$ & $.002^{* *}[.09]$ \\
\hline - ACT.SG & .305 & $.003^{* *}[.16]$ & .652 & .541 & $.067 .[.10]$ & $.013^{*}[.08]$ \\
\hline - MED.PL & .373 & $.068 .[.52]$ & .293 & .539 & .235 & $.032^{*}[.33]$ \\
\hline \multicolumn{7}{|c|}{ Adjustment for metrical position } \\
\hline$-\bar{a} /-\bar{a} n i$ & .476 & $.001^{* * *}$ & .678 & .492 & .757 & .855 \\
\hline$-\bar{u} /-\bar{u} n i$ & .133 & $.008^{* *}$ & .744 & .085 & .162 & .415 \\
\hline -ebhis/-ais & .206 & .052 & .572 & .662 & .123 & $.021^{*}$ \\
\hline$-\bar{a} /$-ena & .644 & $.001^{* * *}$ & .128 & .350 & .393 & .276 \\
\hline$-\bar{a} s a s /-\bar{a} s$ & $.006^{* *}$ & $.001^{* * *}$ & $.017^{*}$ & .132 & $.004^{* *}$ & $.001^{* * *}$ \\
\hline kát/kím & $.043^{*}$ & $.001^{* * *}$ & $.011^{*}$ & .061. & $.028^{*}$ & .059 \\
\hline prim./sec. & .234 & $.001^{* *}$ & .679 & .346 & $.020^{*}$ & $.003^{* *}$ \\
\hline - ACT.SG & .357 & $.013^{*}$ & .815 & .445 & .089 & $.022^{*}$ \\
\hline - MED.PL & .461 & .057. & .381 & .854 & .277 & .069. \\
\hline \multicolumn{7}{|c|}{ Adjustment for prosodic structure } \\
\hline$-\bar{a} /-\bar{a} n i$ & .640 & $.002^{* *}$ & .776 & .757 & .801 & .974 \\
\hline$-\bar{u} /-\bar{u} n i$ & .103 & $.014^{*}$ & .613 & .113 & .082 & .459 \\
\hline -ebhis/-ais & .069 & .072 & .057 & .347 & $.004^{* *}$ & $.035^{*}$ \\
\hline$-\bar{a} /$-ena & .441 & $.011^{*}$ & .064 & .235 & .678 & .254 \\
\hline$-\bar{a} s a s /-\bar{a} s$ & $.004^{* *}$ & $.001^{* * *}$ & $.001^{* * *}$ & .057 . & $.004^{* *}$ & $.001^{* * *}$ \\
\hline \multicolumn{7}{|l|}{ kát/kím } \\
\hline prim./sec. & .308 & .051 & .107 & .367 & .205 & .058 \\
\hline - ACT.SG & .341 & .088 & .258 & .350 & .323 & .134 \\
\hline - MED.PL & & & & & & \\
\hline
\end{tabular}

The upper compartment of Table 3 ("no adjustments") gives the p-values of Freeman-Halton tests for the allomorph distributions studied in this paper (rows) and various stratifications of the RV proposed in previous literature (columns; Arn[old], Old[enberg], Gra[ssmann]; see section 3.1). If a test is significant at the $10 \%$ level, the value of Cramér's index is reported in square brackets (see section 3.3). For the meaning of the asterisks and dots refer to Table 1. The middle compartment ("Adjustment for metrical position") reports the p-values of CMH tests when controlling for the metrical position, and the lower one ("adjustment for prosodic structure") the p-values when controlling for the prosodic structure of words. As expected, 
the p-values of most tests increase (i.e., the results become less significant) when introducing additional control variables. Cells remain empty if the statistical prerequisites for the respective test are not fulfilled.

The values in the upper compartment of Table 3 allow for a number of relevant conclusions. Looking first at the columns (i.e., stratifications proposed in previous research), Table 3 shows that the ratios of most allomorphs found in the appendices postulated by Oldenberg do not differ substantially from the ratios outside this stratum, the only interesting features being kát/kim and -āsas/-ās. Similarly, judging from the reported p-values, Grassmann's strata do not display major differences except for the features kát/kim and NOM/ACC.PL.N $-\breve{\bar{u} /}-\bar{u} n i$. A similar picture emerges for the stratification by books. This outcome thus indicates that none of these three stratifications gets strong statistical support from the allomorph distributions.

The picture changes when we look at the stratification (1-9) (10), that is, Witzel's and especially Arnold's proposals. Judging from the significant p-values of the Freeman-Halton tests, i.e., those smaller than 0.1, the stratification (1-9) (10) finds support from all verbal features, $-\bar{a} s a s /-\bar{a} s$, and kát/kím, and similar, though slightly weaker, effects can be observed for Witzel's proposal; Arnold's stratification shows significant test results for all features but -ebhis/-ais. It should, however, be noted that the corresponding Cramér's indices are comparatively low, especially for Witzel and the (1-9) (10) split. This indicates that much of the statistical significance may be due to large sample sizes (e.g., for $-\bar{a} /-\bar{a} n i$ ) or additional control variables, rather than being caused by non-random differences between the distributions (see the discussion in section 3.3). If we nevertheless assume that the allomorphs indicate non-random linguistic variation that is not solely caused by metrical and prosodic constraints, these three stratifications are more promising than the other proposals.

Turning to the allomorph types, i.e., the rows of Table 3, it can be observed that their tendency to become significant, i.e., to fall below the significance level of 0.1 and thus to point to differences in the strata, is quite unevenly distributed. While -ebhis/-ais only becomes significant for Witzel's proposal, kát/kim is significant for all previous stratifications examined in this paper. In between these two extremes, primary and secondary personal endings of the subjunctive as well as $-\bar{a} s a s /-\bar{a} s$ become significant more often than the remaining allomorphs. Notably, $-\bar{a} /-\bar{a} n i$ and $-\bar{u} /-\bar{u} n i$ do not show significant differences in the (1-9) (10) stratification, although this stratification was the first one to be proposed in Vedic studies and Lanman used both allomorphs (as well as -ebhis/-ais) for his arrangement of the Rigvedic books. At this point, we need to emphasize again that the results presented so far do not allow the conclusion that, for instance, $-\bar{a} /-\bar{a} n i$ do not show any systematic variation in the Rigveda. They merely do not support most of the proposed stratifications.

As mentioned in section 4.1, it is conceivable that the allomorph distributions interact with the metrical position and the prosodic structure of words. The middle and lower compartments of Table 3 report the p-values of CMH tests, with data adjusted for the metrical position (second compartment) and the prosodic structure of the underlying words as control variables (third compartment). When adjusting for the prosodic structure, test results for kát/ kim cannot be reported because both words have the same prosodic pattern. For subjunctive primary vs. secondary med. pl., there are not enough data for running this test. Note that for prim./sec. the prosodic patterns are generated from the inflected word forms and not from the underlying lemmata, as in the case of nominal inflectional endings.

The results in the second compartment of Table 3 conform to our expectations formulated in section 4.1. Since a certain, albeit low amount of linguistic variation can be explained by the metrical position, the p-values tend to become higher and thus less significant than in its 
first compartment (see, for instance, the columns corresponding to (1-9) (10)). As increasing p-values mean an increasing error probability, the results in the second compartment indicate that the differences between the strata become less pronounced when the metrical position is taken into account. The same general trend can be observed for the prosodic structure in the third compartment of Table 3 except for -ebhis/-ais, the p-values of which drop substantially for five out of six proposed stratifications. This result is unexpected, but was foreshadowed by the high Cramér's index of 0.381 in Table 1 .

In order to gain a better grasp of the underlying processes, we inspect the data that lead to the p-value of 0.035 for -ebhis/-ais and (1-9) (10) when controlling for the prosodic structure. Table 4 gives the unadjusted counts of the two allomorphs as well as the counts for seven frequent prosodic patterns. Two of these patterns $(-\smile,--\smile)$ generate a p-value of less than $0.1(10 \%)$ in a Freeman-Halton test. As the p-value for $-\smile$ is more significant than that for - - $\checkmark$ and thus indicates clearer differences between RV 1-9 and RV 10, we extract, for each stratum, the five words that contribute most to the p-value for the pattern $-\smile .^{3}$ Table 5 shows that the highest contributions are made by the three words viśva-, arká-, and éva- in (1-9), which show opposite patterns of allomorph distributions. While arká- and éva-occur almost exclusively with -ais, víśva-clearly prefers the pronominal ending -ebhis. Notably - and contrary to the slight global preference for -ais-devá-also has a higher ratio of -ebhis in both strata, which may be due to the frequent collocation viśve devāa(sa)s "AllGods." In sum, Table 5 suggests that the unexpected significance of -ebhis/-ais observed in Table 3 is mainly due to the inflection of a few words and therefore ultimately to content, but does not provide a deeper insight into the distribution of this allomorph.

Table 4. Distribution of word forms ending in -ebhis/-ais

\begin{tabular}{|c|c|c|c|c|c|c|c|c|}
\hline & \multicolumn{2}{|c|}{ Unadjusted } & \multicolumn{2}{|c|}{$-\smile$} & \multicolumn{2}{|c|}{$\smile \smile$} & \multicolumn{2}{|c|}{$-\smile \smile$} \\
\hline & -ebhis & -ais & -ebhis & -ais & -ebhis & -ais & -ebhis & -ais \\
\hline $1-9$ & 426 & 557 & 266 & 376 & 33 & 34 & 26 & 10 \\
\hline 10 & 72 & 124 & 39 & 86 & 4 & 7 & 7 & 1 \\
\hline \multirow[t]{3}{*}{$\mathrm{FH}$} & 0.398 & & $0.034 *$ & & 0.530 & & 0.674 & \\
\hline & \multicolumn{2}{|c|}{$\smile-\smile$} & \multicolumn{2}{|c|}{$--\smile$} & \multicolumn{2}{|c|}{$\smile \smile \smile$} & \multicolumn{2}{|c|}{$-\smile-\smile$} \\
\hline & -ebhis & -ais & -ebhis & -ais & -ebhis & -ais & -ebhis & -ais \\
\hline $1-9$ & 18 & 66 & 19 & 14 & 29 & 15 & 3 & 15 \\
\hline 10 & 3 & 11 & 2 & 8 & 7 & 1 & 2 & 3 \\
\hline FH & 1.000 & & 0.072 . & & 1.000 & & 0.290 & \\
\hline
\end{tabular}

The forms are split by the prosodic structure of the stem they belong to. In Table 4, the rows labeled FH give the p-values of Freeman-Halton tests for the respective subtables.

3. We calculate the word-wise contributions to a $\chi^{2}$ statistics and order the words by their decreasing contributions. 
Table 5. Word-wise contributions to the chi-squared test statistics for the allomorph -ebhis/ - ais and the prosodic structure $-\smile$ (see n. 3 )

\begin{tabular}{|l|l|l|l|l|l|l|l|}
\hline \multicolumn{4}{|c|}{$1-9$} & \multicolumn{5}{c|}{10} \\
\hline Word & \multicolumn{1}{|c|}{-ebhis } & \multicolumn{1}{|c|}{-ais } & \multicolumn{1}{c|}{$\chi^{2}$} & Word & -ebhis & -ais & \\
\hline vísva- & 26 & 4 & 25.296 & jyéșța- & 3 & 0 & 6.62 \\
\hline arká- & 3 & 38 & 19.67 & devá- & 10 & 7 & 6.04 \\
\hline éva- & 0 & 25 & 17.69 & rudrá- & 4 & 1 & 5.55 \\
\hline devá- & 41 & 31 & 7.14 & víśva- & 3 & 1 & 3.57 \\
\hline áśva- & 6 & 25 & 6.23 & arká- & 0 & 5 & 2.27 \\
\hline
\end{tabular}

\subsection{Cluster Analysis}

In the second set of experiments, we test which groupings (clusterings) of Rigvedic books can be induced from the distributions of allomorphs without additional prior assumptions and how these automatically detected clusterings relate to results proposed in previous literature. As described in Section 3.3, we enumerate all 115,975 possible partitions of the ten books of the RV ((1) (2-10), (2) (1,3-10), . ., (1-3) (4) (5-9) (10), .., (1-10)), determine how well a binomial clustering model based on allomorph counts explains each of these partitions, and finally use the BIC for balancing the fit of the model to the data and its complexity, i.e., the number of clusters used. This strategy produces a ranking of clusterings that is a compromise between the model complexity (Occam's razor prefers as few clusters as possible) and its fit to the data, i.e., its explanatory power. Since the tests in section 4.2 did not indicate strong differences between the books (see Table 3, col. 1), we do not expect to find any really salient stratification when using a clustering algorithm.

The evaluation of the results suggests that only the following nine clusters are differentiated enough to be considered as individual solutions. ${ }^{4}$ As for the stratification (1-9) (10), books assigned to the same cluster are enclosed in round brackets:

$(1-9)(10)$

$(1,3-9)(2,10)^{*}$

$(1-10)$

$(1,3,5-9)(2,4,10)$

$(1,3,6-9)(2,4-5,10)$

$(1-3,5-9)(4,10)$

$(1,3-4,6-9)(2,5,10)$

$(1,3-6,8-9)(2,7,10)^{*}$

$(1-4,6-9)(5,10)$

Notably, the best model, judging from its BIC, is the most widely accepted split (1-9) (10). The special position of RV 10 suggested by this result is further emphasized by the remaining clusters (except for (1-10)) all of which contain this book in their smaller partition. This trend which separates RV 10 from the rest of the text can also be confirmed using a

4. When the BIC values are plotted in decreasing order (not shown), it can be observed that the resulting curve has a turning point at around the ninth clustering ("elbow"), indicating that clusters after this position do not provide much more distinctive information. 
statistical test of significance. ${ }^{5}$ The model without further substructure, i.e., (1-10), occupies the third position. Taking together the facts that none of the top clusters consists of more than two groups and that the BIC makes a compromise between the model complexity, which is lowest for (1-10), and its adaptation to the data, this result suggests that the distribution of allomorphs does not favor an overly complex stratification of the Rigveda.

While the results discussed so far appear to provide a strong argument for the (1-9) (10) split, one should keep in mind that the clustering results are not stable, as they are based on a low number of linguistic markers. In an earlier version of our experiments (details not reported), we included, for example, the allomorph $-a y \bar{a} /-\bar{a}$, but omitted $-\bar{a} s a s /-\bar{a} s$. While (1-10) was now found at the first position in this setting, (1-9) (10) occurred only at position 27, and the algorithm marked books 3,9 , and again 10 as differing from the rest of the RV (note, however, that Wüst considered RV 3, 4, 7, and 9 to constitute the oldest part of the $\mathrm{RV})$. This outcome suggests that the results of automatic as well as manual groupings of the Rigvedic books, as proposed earlier by Lanman, Arnold, and subsequent scholars, should be taken with greatest caution as long as they are based on a low number of features.

The conclusion that, given our linguistic data, the top nine clusterings listed above provide only weak evidence for any stratification of the Rigveda is further corroborated by testing whether the top clusters with two groups differ with regard to their joint allomorph distributions. ${ }^{6}$ Such a test provides significant results only for clusters 2 and 8 which are marked with an asterisk in the above listing, whereas (1-9) (10) does not become significant in this test. As was foreshadowed by Table 3, there seem to be linguistic differences between RV 10 and the rest of the text, but they are not strong enough to be statistically significant when the joint evidence of the allomorph distributions is considered.

\section{SUMMARY AND CONCLUSIONS}

Previous research has made proposals concerning the internal organization and stratification of the Rigveda by evaluating various distributions of contextual and linguistic parameters. Taking a quantitative approach, this paper addresses the question if a set of linguistic allomorphs that historically formed one of the starting points for such studies is distributed in a way that coincides with, and therefore lends support to, proposed stratifications of the Rigveda. We address this question from two different angles. In section 4.2 we examine if these stratifications show significant differences with respect to these allomorphs, and in section 4.3 we apply an exploratory approach and assess if organizational stratifications by books can be induced from the distributions of these allomorphs.

Overall, the organizational stratification that groups books 1-9 against book 10, i.e., (1-9) (10), Arnold's mixed stratification, which is based on content, metrical form, and linguistic features, and Witzel's model show a certain degree of correlation with the observed allomorph distributions (see Table 3). While the split (1-9) (10) gets further support by the cluster analysis in section 4.3, the results of this approach are numerically not stable due to the low number of features examined and should therefore be considered with caution.

5. When a co-occurrence matrix of the top five clusterings is created (Fred and Jain 2005), the column sums of book 10, i.e., the number of other books with which this book is clustered, is significantly lower than that for the other Rigvedic books. We test for significance using one-sided binomial tests for RV 10, the success ratio of which is estimated via MLE from the column sums for RV $1-9$. Here, books $2\left(0.0031^{* *}\right)$ and $10(p<0.00001)$ obtain (highly) significant p-values of less than $1 \%$, while none of the other books gets below the $10 \%$ significance level.

6. For each clustering, we split the bookwise table of allomorph ratios into the proposed groups and test if the samples (= books of the Rigveda contained in the individual clusters) differ significantly with regard to the joint distribution of allomorph ratios. We use the randomization test described by Hothorn et al. 2008. 
Other proposals, such as Oldenberg's and Grassmann's appendices, do not show systematic variation in our tests. The support for Arnold's proposal does not come as a surprise since the allomorphs studied in this paper form a subset of the parameters he considered. However, as we show in section 4.2, the support for Arnold's and Witzel's proposals as well as (1-9) (10) becomes substantially less salient when more complex interactions between linguistic (prosodic structure, word length, syntax) and contextual factors (verse type, pāda structure, content) are taken into consideration. At this point, our paper can only show the direction for more complex models that may be developed in future research.

To be sure, our assessment does not prove that the stratifications tested in section 4 are not grounded on systematic linguistic variation. They simply do not emerge when we assess, using statistical tests of significance, the set of allomorphs chosen in this paper, which still forms the (implicit) foundation of many studies examining the stratification of the Rigveda. As a result, this paper neither proposes a new stratification of the Rigveda nor lends strong support to any existing proposal.

In conclusion, two major results emerge from the implementation of quantitative approaches we performed in this article. First, in terms of methods we have substantiated the importance of using sound statistical methods for testing philological hypotheses such as the stratification of the Rigveda. Lanman, for example, simply sorted Rigvedic books by the ratios of a set of allomorphs, and the same approach was applied by many of his successors. Trying to infer text-historical conclusions from such ratios without assessing their statistical significance, however, is by no means a valid procedure. As for the data, the actual contribution of a single feature (linguistic in this case) often only becomes apparent when large samples are considered. In recent years a growing number of annotated digital resources has become available, such as VedaWeb (Kiss et al. 2019), on which we relied in this paper, the Treebank of Vedic Sanskrit (Hellwig et al. 2020), the online edition of the Paippalāda Recension of the Atharvaveda (Leach et al. 2020), and the Digital Corpus of Sanskrit (Hellwig 2010-20). The future clearly belongs to shared open resources that facilitate and enhance philological research from both a qualitative and a quantitative perspective. It is sometimes seen as a drawback that these resources, even when manually curated, are not error free and thus prone to produce unreliable results. At this point, statistical methods again enter the picture: since many statistical methods originated in the social sciences and related disciplines, they are robust enough to cope with uncertainty in the data, in the sense that the effect that uncertainty exerts on the results can be estimated. While the detailed philological examination of individual verses or hymns needs access to editions of the highest quality, statistical approaches that focus on larger text units work well even with less meticulously created resources. However, careful qualitative work is the foundation on which any solid philology stands. We therefore advocate the use of appropriate quantitative methods in combination with thorough philological scrutiny and all available resources. The outcome of such an integrative approach is likely to substantially contribute to a better understanding of many linguistic, textual, sociocultural, and spatio-temporal aspects of the Vedic world.

Second, our results suggest that the allomorph alternations used to stratify the Rigveda in previous literature and tested in this article appear to be only loosely coupled with the structure of the Rigveda. Given these features, the Rigveda is likely more homogeneous than often assumed, lining up with its phonological uniformity. In our opinion, this outcome does not impose any restrictions on the time, social milieu, or geographical setting in which the text, or parts of it, was composed: As emphasized above, at least some, indeed most, of the morphological variants studied here were already part of the common Rigvedic language from the beginning and could thus freely be used by the poets throughout the period of 
composition. Therefore, the fact that they do not lend strong support to most stratification hypotheses brought forward in previous literature does not, in our opinion, allow or encourage the conclusion that the text was composed in a short period of time or in a clearly limited geographical area. Future research aiming at stratifying this text may therefore want to (re)consider other types of linguistic evidence. Promising candidates are derivational processes as described, for example, in Wackernagel and Debrunner 1930-57: II.2 and already studied in Wüst 1928, or variations in the lexicon, where Wackernagel (1896: xiv) expected to find the most relevant changes in the Vedic language. Previous attempts at correlating the lexicon with the structure of the Rigveda were not widely accepted in the scholarly community, because the interactions between the textual content and its lexical realization were not (and actually could not be) controlled systematically. Adequate robust quantitative methods are now available. This opens up interesting perspectives for future research.

\section{BIBLIOGRAPHY}

Agresti, Alan. 1992. A Survey of Exact Inference for Contingency Tables. Statistical Science 7.1: 131-53.

- 2007. An Introduction to Categorical Data Analysis. Hoboken, NJ: John Wiley \& Sons, Inc.

Arnold, Edward V. 1897a. Literary Epochs in the Rigveda. Zeitschrift für vergleichende Sprachforschung auf dem Gebiete der indogermanischen Sprachen 34.3: 297-344.

- 1897b. Sketch of the Historical Grammar of the Rig and Atharva Vedas. JAOS 18: 203-353. . 1905. Vedic Metre in Its Historical Development. Cambridge: Cambridge Univ. Press.

Bergaigne, Abel. 1886. La saṃhitā primitive du Rig-Veda. Journal asiatique 8.8: 193-271.

—. 1887. Nouvelles recherches sur la samhitā primitive du Rig-Veda. Journal asiatique 8.9: 191-287.

Best, Karl-Heinz. 2003. Spracherwerb, Sprachwandel und Wortschatzwachstum in Texten: Zur Reichweite des Piotrowski-Gesetzes. Glottometrics 6: 9-34.

Bloomfield, Maurice. 1899. The Atharvaveda. Strassburg: Karl J. Trübner.

Blythe, Richard A., and William Croft. 2012. S-Curves and the Mechanisms of Propagation in Language Change. Language 88: 269-304.

Bortz, Jürgen, and Gustav A. Lienert. 2003. Kurzgefasste Statistik für die klinische Forschung. Heidelberg: Springer Medizin Verlag.

Brereton, Joel P., and Stephanie W. Jamison. 2020. The Rigveda: A Guide. New York: Oxford Univ. Press. https://doi.org/10.1093/oso/9780190633363.001.0001.

Cardona, George. 2017. The Documentation of Indic. In Handbook of Comparative and Historical Indo-European Linguistics, ed. Jared Klein, Brian Joseph, and Matthias Fritz. Pp. 309-25. Berlin: W. de Gruyter. https://doi.org/10.1515/9783110261288-025.

Coenen, Pascal, and Michael Frotscher. 2020. The Nominative/Vocative Plural of Vedic Masculine a-Stems in Complex Nominal Expressions. Indogermanische Forschungen 125: 165-215.

Dahl, Eystein. 2010. Time, Tense and Aspect in Early Vedic Grammar: Exploring Inflectional Semantics in the Rigveda. Leiden: Brill.

Dawson, Hope C. 2005. Morphological Variation and Change in the Rigveda: The Case of -au vs. $-\bar{a}$. PhD. diss. Ohio State Univ. http://rave.ohiolink.edu/etdc/view?acc_num=osu1110469087.

Etter, Annemarie. 1985. Die Fragesätze im Rgveda. Berlin: W. de Gruyter.

Fleischer, Jürg. 2012. Grammatische und semantische Kongruenz in der Geschichte des Deutschen: Eine diachrone Studie zu den Kongruenzformen von ahd. wib, nhd. weib. Beiträge zur Geschichte der deutschen Sprache und Literatur 134: 163-204.

Fosse, Lars Martin. 1997. The Crux of Chronology in Sanskrit Literature: Statistics and Indology. A Study of Method. Oslo: Scandinavian Univ. Press.

Fred, Ana L. N., and Anil K. Jain. 2005. Combining Multiple Clusterings Using Evidence Accumulation. IEEE Transactions on Pattern Analysis and Machine Intelligence 27.6: 835-50. 
García Ramón, José Luis. 2009. Primär- und Sekundärendungen im Konjunktiv im Vedischen: Deixis und Sprechakt. In Pragmatische Kategorien: Form, Funktion und Diachronie, ed. Elisabeth Rieken and Paul Widmer. Pp. 79-91. Wiesbaden: Reichert.

Gonda, Jan. 1975. Vedic Literature (Samhitās and Brāhmanas). Wiesbaden: Otto Harrassowitz.

Grassmann, Hermann. 1873-75. Wörterbuch zum Rig-Veda. Leipzig: Brockhaus.

. 1876-77. Rig-Veda: Übersetzt und mit kritischen erläuternden Anmerkungen versehen. 2 vols. Leipzig: Brockhaus.

Hellwig, Oliver. 2010-20. DCS - the Digital Corpus of Sanskrit. Berlin. http://www.sanskrit-linguistics.org/dcs/index.php.

Hellwig, Oliver, Elia Ackermann, Salvatore Scarlata, and Paul Widmer. 2020. The Treebank of Vedic Sanskrit. In Proceedings of the 12th Conference on Language Resources and Evaluation (LREC 2020). Pp. 5137-46. http://www.lrec-conf.org/proceedings/lrec2020/pdf/2020.lrec-1.632.pdf.

Hill, Eugen. 2018. Differential Subject Marking in Old Indo-Iranian: A Preliminary Functional Analysis and the Etymology of the Marker. In Klasse Person: Festschrift für Wolfgang Schulze anlässlich seines 65. Geburtstags am 29. Januar 2018, ed. Andreas Hölzl and Peter-Arnold Mumm. Pp. 93-109. Munich: Peniope.

Hoffmann, Karl. 1967. Der Injunktiv im Veda: Eine synchronische Funktionsuntersuchung. Heidelberg: Winter.

Hothorn, Torsten, Kurt Hornik, Mark van de Wiel, and Achim Zeileis. 2008. Implementing a Class of Permutation Tests: The Coin Package. Journal of Statistical Software, Articles 28.8: 1-23.

Jamison, Stephanie W., and Joel P. Brereton, tr. 2014. The Rigveda: The Earliest Religious Poetry of India. 3 vols. New York: Oxford Univ. Press.

Keydana, Götz. 2013. Infinitive im Rgveda: Formen, Funktion, Diachronie. Leiden: Brill.

Kiss, Börge, Daniel Kölligan, Francisco Mondaca, Claes Neuefeind, Uta Reinöhl, and Patrick Sahle. 2019. It Takes a Village: Co-Developing Vedaweb, a Digital Research Platform for Old Indo-Aryan Texts. In Proceedings of the Twin Talks Workshop at DHN 2019: Co-Located with Digital Humanities in the Nordic Countries (DHN 2019), ed. Steven Krauwer and Darja Fišer. Pp. 35-44. Utrecht: CLARIN ERIC. http://ceur-ws.org/Vol-2365/.

Lanman, Charles R. 1872. A Statistical Account of Noun-Inflection in the Veda. JAOS 10: 325-601.

Leach, Robert, Oliver Hellwig, Thomas Zehnder, Angelika Malinar, and Paul Widmer. 2020-. Paippalāda Recension of the Atharvaveda: Online Edition (Beta). http://www.atharvaveda-online. uzh.ch.

Lowe, John J. 2015. Participles in Rigvedic Sanskrit: The Syntax and Semantics of Adjectival Verb Forms. Oxford: Oxford Univ. Press.

Macdonell, Arthur A. 1910. Vedic Grammar. Strassburg: Trübner.

Malzahn, Melanie. 2001. Sandhiphänomene im Rigveda als Reflexe von Archaismen und Dialektismen. PhD. diss., Universität Wien. https://doi.org/10.25365/thesis.3432.

Nevalainen, Terttu. 2015. Descriptive Adequacy of the S-Curve Model in Diachronic Studies of Language Change. Studies in Variation, Contacts and Change in English 16. https://varieng.helsinki.fi/ series/volumes/16/nevalainen/index.html.

Oldenberg, Hermann. 1888. Die Hymnen des Rigveda: Band I. Metrische und textgeschichtliche Prolegomena. Berlin: Wilhelm Hertz.

Pirart, Éric. 2001. Deux sandhi védiques méconnus. Indo-Iranian Journal 44.1: 59-71.

Pisani, Vittore. 1929. Review of Wüst 1928. Rivista degli studi orientali 12: 332-45.

Porzig, Walter. 1923. Die Hypotaxe im Rigveda. Indogermanische Forschungen 41: 210-303.

Poucha, Pavel. 1942a. Schichtung des Rogveda: Bestimmung des relativen Alters der Lieder des Rggeda mit Hilfe zahlenmässiger Berechnung. I. Archív orientální 13: 103-41.

. 1942b. Schichtung des Rgveda: Bestimmung des relativen Alters der Lieder des Rgveda mit Hilfe zahlenmässiger Berechnung. II. Archív orientální 13: 225-69.

- 1944. Schichtung des Rogveda: Bestimmung des relativen Alters der Lieder des Rgveda mit Hilfe zahlenmässiger Berechnung. III. Archív orientální 15.1: 65-86. 
R Core Team. 2018. R: A Language and Environment for Statistical Computing. Vienna: R Foundation for Statistical Computing. https://www.R-project.org/.

Roth, Rudolph. 1856. Abhandlung über den Atharva Veda. Tübingen: Fues.

Schwarz, Gideon. 1978. Estimating the Dimension of a Model. The Annals of Statistics 6.2: 461-64.

Tan, Pang-Ning, Michael Steinbach, Anuj Karpatne, and Vipin Kumar. 2019. Introduction to Data Mining. New York: Pearson Education.

Thieme, Paul. 1964. Gedichte aus dem Rig-Veda. Stuttgart: Reclam.

VedaWeb: Online Research Platform for Old Indic Texts. 2018-. https://vedaweb.uni-koeln.de/.

Wackernagel, Jacob. 1896. Altindische Grammatik, vol. 1: Lautlehre. Göttingen: Vandenhoeck \& Ruprecht.

Wackernagel, Jacob, and Albert Debrunner. 1930-57. Altindische Grammatik. 3 vols. 2nd ed. Göttingen: Vandenhoeck \& Ruprecht.

Witzel, Michael. 1989. Tracing the Vedic Dialects. In Dialectes dans les littératures indoaryennes, ed. Colette Caillat. Pp. 97-265. Paris: Collège de France.

- 1995. Rgvedic History: Poets, Chieftains, and Polities. In The Indo-Aryans of Ancient South Asia: Language, Material Culture and Ethnicity, ed. George Erdosy. Pp. 307-52. Berlin: W. de Gruyter.

- 1997. The Development of the Vedic Canon and Its Schools: The Social and Political Milieu. In Inside the Texts, beyond the Texts, ed. Michael Witzel. Pp. 257-345. Columbia, MO: South Asia Books.

- 2003. Das alte Indien. München: Beck.

Witzel, Michael, and Toshifumi Gotō. 2007. Rig-Veda: Das heilige Wissen, vol. 1: Erster und zweite Liederkreis. Frankfurt am Main: Verlag der Weltreligionen.

Wüst, Walther. 1928. Stilgeschichte und Chronologie des Rgveda. Leipzig: Deutsche Morgenländische Gesellschaft. 